\title{
La escritura académica como proceso epistémico en la enseñanza del derecho penal
}

\section{Caviedes Estanislao Escalante-Barreto*}

Universidad Nacional de Colombia

ceescalanteb@unal.edu.co

\section{Resumen}

La superación de concepciones pedagógicas basadas en modelos conductistas y la implementación de otras formas metodológicas pueden llevar al "aprendizaje crítico natural". Este es un escenario propicio para generar nuevas formas de construir conocimiento, considerando a los partícipes del acto educativo como sujetos de interacción pedagógica. Este contexto permite identificar la escritura y la alfabetización académica como procesos epistemológicos de construcción y transformación del conocimiento penal. Por lo que se plantea como reto la necesidad de reconocer que la escritura es un proceso que se construye de manera permanente por comunidades académicas y no por individuos aislados. Este proceso se caracteriza por permitir la construcción de conocimiento nuevo, reflexivo y analitico en el aprendizajelenseñanza, el cual debe ser reconocido como parte del proceso pedagógico y de reflexión sobre el acto educativo para transformar la enseñanza del derecho penal.

\section{Palabras clave}

Pedagogía universitaria, escritura académica, enseñanza universitaria, derecho penal, pensamiento crítico (Fuente: Tesauro de la Unesco).

Recepción: 2014-11-12 | Envío a pares: 2015-01-24 | Aceptación por pares: 2015-06-21 | Aprobación: 2015-08-05 


\title{
Academic Writing as an Epistemic Process in Teaching Criminal Law
}

\begin{abstract}
Overcoming pedagogical concepts based on behavioral models and implementing other methodological styles can lead to natural critical learning. This is an environment conducive to generating new ways of building knowledge, by considering the participants in educational action as subjects of pedagogical interaction. Academic writing and literacy can be identified in this context as epistemological processes for the construction and transformation of knowledge on criminal law. This is because it confronts the need to acknowledge writing as a process that is constructed permanently by academic communities and not by isolated individuals. This process is characterized as being one that makes it possible to build new, thoughtful and analytical knowledge on teaching/learning. It should be recognized as an element in the educational process and as part of thinking on educational action, so as to transform the way criminal law is taught.
\end{abstract}

\section{Keywords}

University teaching, academic writing, university education, criminal law, critical thinking (Source: Unesco Thesaurus). 


\section{A escrita acadêmica como processo epistêmico no ensino do direito penal}

\section{Resumo}

A superação de concepções pedagógicas baseadas em modelos comportamentais e a implementação de outras formas metodológicas podem levar à "aprendizagem crítica natural". Este é um cenário propício para gerar novas formas de construir conhecimento uma vez que se consideram os participantes do ato educativo como sujeitos de interação pedagógica. Esse contexto permite identificar a escrita e a alfabetização acadêmica como processos epistemológicos de construção e transformação do conhecimento penal. Por isso, propõe-se como desafio a necessidade de reconhecer que a escrita é um processo que se constrói de maneira permanente por comunidades acadêmicas e não por indivíduos isolados. Esse processo é caracterizado por permitir a construção de conhecimento novo, reflexivo e analítico no ensino-aprendizagem, o qual deve ser reconhecido como parte do processo pedagógico e de reflexão sobre o ato educativo para transformar o ensino do direito penal.

\section{Palavras chave}

Pedagogia universitária, escrita acadêmica, ensino superior, direito penal, pensamento crítico. (Fonte: Tesauro da Unesco). 


\section{Introducción}

La escritura como proceso epistémico' puede ser asumida como un componente de formación transversal en la comprensión y la práctica del derecho penal, no solo para la buena práctica de la profesión, sino para que el estudiante construya conocimiento, pueda hacer buen uso del estado del arte de su disciplina con una comprensión profunda del mismo, reconstruya posibilidades de reflexión, aporte a la comunidad científica o académica a la que empieza a pertenecer como profesional en formación y analice con sentido crítico las decisiones judiciales en la materia.

No obstante lo anterior, en la enseñanza y práctica del derecho no es común reflexionar sobre la forma como se escribe o la intensidad de su práctica; de hecho, la producción escrita del estudiante se limita a la reproducción resumida de manuales, conceptos y teorías o a la reproducción escrita de contenidos en los exámenes y las evaluaciones periódicas. De otra parte, en el componente curricular o en los programas académicos se suele hacer énfasis en la oralidad o la argumentación, como si escritura y oralidad fueran dos realidades excluyentes, totalmente diversas, que se pudieran fragmentar sin ningún tipo de relación.

En efecto, si se revisan con atención los programas académicos de la carrera de derecho, ${ }^{2}$ en los mismos no aparece una asignatura al respecto y tampoco hay evidencia de orientaciones metodológicas, de alfabetización o de reflexión documentada de los docentes y para los docentes, que permita comprobar preocupación alguna sobre la necesidad de pensar la escritura como forma de producir conocimiento, de reflexionar o de transformar el que se tiene.

La escritura tiene sus propias discusiones en el ámbito de la investigación pedagógica. Una clara

1 Sobre la escritura como proceso epistémico y la alfabetización, véase Guzmán (2012, p.12).

2 Para el efecto se revisó el currículo académico de las universidades Nacional de Colombia, La Sabana, De los Andes, Externado de Colombia y Santo Tomás. muestra de los problemas que suscita la escritura en el ámbito académico la refleja la investigación realizada sobre los géneros académicos en la universidad (Murillo, 2015) que da cuenta de los principales hallazgos sobre la lectura y la escritura en dicho ámbito. De una parte, encuentra la investigación que, en América Latina en general y en Colombia en particular, las universidades cuentan con uno o dos cursos de enseñanza de la lectura y la escritura en las diversas disciplinas, de lo cual se derivan dos consecuencias: la primera es que la lectura y la escritura son procesos "acabados", de acuerdo con lo cual los estudiantes llegan a la universidad con poca capacidad para escribir, dados los procesos deficientes de los docentes de secundaria o las condiciones precarias de la sociedad. De otra parte, se encuentra la lectura y la escritura como procesos dinámicos en continua evolución, de manera que los estudiantes, al ingresar a la universidad, entran a una comunidad discursiva, escenario en el que deberán aprender esos nuevos géneros discursivos en el ámbito de la disciplina particular (Murillo, 2015a, p. 19).

La disyuntiva que plantea el estudio es si ante esta situación se debe enseñar la escritura y la lectura en cursos remediales o de nivelación, de manera que todos los estudiantes adquieran un nivel estándar de lo que no aprendieron en la educación media, o si, por el contrario, se debe enseñar la escritura y la lectura en cursos de carácter discursivo y dialéctico en los que se considere que el estudiante ya conoce lo que debía conocer en su proceso inicial, pero que, al entrar en la universidad, lo debe transformar y reorientar a la escritura de su propia disciplina. Las líneas de investigación indagadas en dicho trabajo dan cuenta de la existencia de una tendencia, propuesta en diversos estudios, 3 según la cual los

3 Una reciente reconstrucción del estado del arte sobre la escritura y la lectura en la universidad se puede encontrar en las últimas publicaciones de investigación pedagógica de la Universidad del Cauca. En primer lugar, la ya citada investigación cualitativa sobre los géneros académicos en la universidad (Murillo, 2015b) y, de la misma autora, El estado del arte de la lectura y la escritura en la universidad (2015a); 
profesores de las disciplinas deben continuar con el proceso de enseñanza de los géneros académicos, pues, según se dice, "son ellos los que a través de la escritura, la lectura, la interacción en cada una de sus clases y mientras enseñan los contenidos, harán que sus estudiantes ingresen a la comunidad de conocimiento de un determinado campo del saber científico" (Murillo, 2015b, pp. 20-21).

En este contexto, el estado del arte sobre escritura académica plantea la necesidad, transversal y de corresponsabilidad en todos los niveles de formación, de introducir la alfabetización y la escritura como componentes de permanente práctica y aprendizaje del docente. Así mismo, se plantea la necesidad de reflexionar sobre estos componentes y de estructurarlos y valorarlos desde el punto de vista epistémico, ${ }^{4}$ para superar prácticas para las cuales ello es indiferente en la enseñanza universitaria del derecho, especialmente en las actuales tendencias de construcción de escenarios de prácticas procesales orales. En este contexto, se desecha la escritura, sin mayor análisis, desde el punto de vista de la educación, y se la ve, en cambio, como forma exclusivamente disciplinar en el ámbito del procedimiento penal oral. En otras palabras, la práctica e implementación de escenarios de litigio profesional oral ha repercutido en la formación, al transformar la enseñanza en escenarios de oralidad; es decir, que la universidad, sin mediar una reflexión pedagógica, ha incursionado en la oralidad, en detrimento, en

finalmente, las investigaciones sobre la escritura académica de la profesora Rosa Julia Guzmán (2012).

4 En este sentido, se plantea que el proceso de escritura no es de aquellos que se inician y culminan en el preescolar o la educación media, sino que, por ser de permanente construcción, va hasta la formación de posgrado y no de manera aislada, en materias concretas o talleres de competencia. Como compromiso de docencia y formación, debe ser asumido por docentes, estudiantes e institucionalmente, como lo muestra Carlino en la experiencia de las universidades australianas, canadienses y estadounidenses que, de acuerdo con su investigación, asumen la alfabetización académica como parte esencial de los procesos de formación disciplinar (2003, p. 13). algunos casos con omisión absoluta, de la escritura académica en el proceso de formación.

El presente escrito tiene como propósito demostrar la importancia de que los estudiantes de derecho adquieran una visión comprensiva de la escritura académica como proceso y como oportunidad de construir su propio conocimiento, de comprender la disciplina y resolver problemas jurídicos desde la práctica reflexiva de su propia escritura, superando visiones meramente instrumentales de la misma o vacías de reflexión. Para lograr dicha finalidad, en el artículo se plantea, en primer lugar, la caracterización de la enseñanza en el derecho y especialmente en el derecho penal, luego de lo cual se estudia la importancia de comprender la escritura como un proceso epistémico complejo. Así mismo, abordaremos la necesidad docente de evaluar en el acto educativo los propósitos que se plantea, cómo se comunica con sus estudiantes, su interacción y la asertividad en lo que les transmite y lo que espera que comprendan frente a los resultados obtenidos; en tercer lugar, se describen las características de la escritura de los estudiantes de la carrera de Derecho de la Universidad de La Sabana, con sus creencias y contenidos, para finalmente, proponer, con base en los insumos anteriores, una matriz evaluativa de la escritura académica de textos analíticos en el área del derecho penal. Como conclusión, se espera aportar a la reflexión sobre la práctica docente y la autoevaluación pedagógica y, finalmente, ofrecer una matriz que permita, tanto a docentes como a estudiantes de derecho penal, reconocer la forma y el contenido que se evalúa en un texto de naturaleza analítica y argumentativa.

El presente documento es un avance de investigación en el marco de la Maestría en Pedagogía de la Universidad de La Sabana, en la tesis que lleva por título "Valoración de la práctica pedagógica en la enseñanza del derecho: una experiencia de constructivismo social y enseñanza para la comprensión del Derecho Penal General", proceso de intervención en el aula en el que se incluyeron prácticas y activi- 
dades pedagógicas para la transformación del acto educativo, entre ellas, el ensayo como proceso epistémico en la escritura académica, guiado por la doctora Rosa Julia Guzmán. De acuerdo con lo anterior, desde el punto de vista metodológico, el trabajo se enmarca dentro de una investigación más amplia que tuvo como soporte metodológico un enfoque cualitativo de tipo participativo, ${ }^{5}$ sin dejar de lado algunos aspectos de la dimensión objetiva de la realidad, cuantificables y observables empíricamente (Bonilla y Rodríguez, 1997), modelo en el que debimos conocer y aplicar las herramientas y los presupuestos teóricos que subyacen a la construcción social de la realidad y, en especial, a la construcción de conocimiento en procesos sociohistóricos que afectan el acto educativo y al educador.

La tesis que sustenta la postura metodológica en la que se enmarca el presente trabajo, como avance de la tesis de maestría, hace referencia a que la investigación educativa en el aula de clases es principalmente cualitativa y requiere de un modelo complejo de comprensión de la realidad social en el que se debe asumir una postura epistemológica que ubique al investigador en el plano de sujeto de interacción investigativa y educativa, por lo que es, a su vez, actor constructor de realidad social e investigador observador de la misma. Esto se traduce en la comprensión de la relación sujeto-sujeto en este tipo de investigación. Para tal efecto, se tienen en cuenta los problemas epistemológicos y metodológicos a los que se enfrenta el investigador y se parte del presupuesto según el cual los problemas encontrados están relacionados con la definición metodológica para abordar la práctica pedagógica, la interacción con los estudiantes y la construcción colectiva de conocimiento a partir de la experiencia.

5 Jiménez Lozano denomina a esta perspectiva como aquellas "alternativas hermenéuticas y de la teoría social crítica" (1994)

\section{Procesos y métodos de enseñanza en el derecho penal}

En el ejercicio de la actividad docente en el ámbito universitario y en la disciplina jurídica, es común observar a excelentes profesionales o abogados en la ejecución de la cátedra universitaria. Ejercicio que en algunas ocasiones está acompañado de una sólida formación académica, dominio del conocimiento en la comunidad científica y, en ocasiones, amplia experiencia en la producción literaria de textos jurídicos o de investigación en el área de dominio.

No obstante la anterior fortaleza disciplinar, los docentes en el ámbito jurídico no siempre se preguntan por su quehacer como profesores, por la metodología de enseñanza de su disciplina o por las alternativas para mejorar los niveles de comprensión de sus alumnos. En este sentido, en la práctica docente del abogado suele estar ausente la reflexión sobre la práctica del acto educativo. Así, es posible que los abogados de excelencia académica o profesional ejerzan la docencia sin tener la formación docente adecuada o sin que hayan reflexionado en el sinnúmero de posibilidades que proporciona la pedagogía, tanto para enseñar su área disciplinar como para mejorar la comprensión de la misma por parte de sus interlocutores en un aula de clases.

El anterior planteamiento permite bosquejar algunas reflexiones sobre "la forma" en la enseñanza del derecho. Veamos algunos ejemplos:

1. Los docentes con fuerte formación dogmática o teórica positivista pueden estar muy cercanos a formas tradicionales de enseñanza, esto es, a través de la cátedra magistral o modelos de enseñanza conductista. Independiente de la valoración que se pueda hacer de este modelo, es posible que el estudiante participe muy poco en el proceso de enseñanza y adopte una posición pasiva en la que "aprende" lo que enseña el profesor. ${ }^{6}$

6 En este sentido, el estudiante es un receptor pasivo de contenidos previamente definidos o diseñados en manuales 
2. Podría plantearse la enseñanza del derecho de aquellos docentes que trabajan su clase a partir de la experiencia y el estudio de casos. Modelo que puede hacer que el estudiante sea partícipe de debates y adquiera competencias comunicativas más sólidas que en el anterior.

3. Algunos profesores parten del reconocimiento del participante como un sujeto activo en la construcción de su propio conocimiento. Modelo que puede hacer de las sesiones presenciales un escenario propicio para adquirir experiencia en solución de problemas, producción de conocimiento y comprensión del área disciplinar, más allá de la mera recordación y memorización conceptual de contenidos, y haciendo un esfuerzo por mejorar competencias argumentativas, orales y escritas.

Con independencia de las fortalezas o debilidades que seguramente tienen los ejemplos planteados, la actividad del docente en el derecho debería integrar una constante reflexión sobre la práctica y en especial sobre los últimos aspectos señalados en el ejemplo tres, esto es, la oralidad y la escritura. Dicha reflexión, además, debe tener presente la percepción, motivación y necesidad del sujeto de interacción educativa, esto es, al estudiante universitario, especialmente como sujeto reflexivo y constructor de su propio conocimiento.

Ahora bien, si se observa el campo del derecho penal, la complejidad aumenta al tener este diversos niveles de comprensión, análisis y explicación. Históricamente el derecho penal ha estado íntimamente relacionado con el desarrollo de la ciencia y de las disciplinas sociales. Dependiendo del momento histórico dado, la teoría del derecho penal ha sido tributaria de un modelo de explicación diverso. Por ejemplo, del racionalismo, del positivismo científico, del causalismo

técnicos de la disciplina, documentos de investigación, decisiones judiciales o trabajos elaborados con antelación por el profesor. valorativo, de la fenomenología, del funcionalismo y, últimamente, de la teoría de los sistemas y del riesgo, cada una de las cuales ha buscado una explicación o comprensión del derecho penal relacionada con los presupuestos teóricos y metodológicos de su propia perspectiva teórica.

Aunado a lo anterior, la práctica penal tiene que ver con hechos y demostración de los hechos, con normas jurídicas y con valoración de los primeros frente a estas. Igualmente, con la conducta de seres humanos y la reacción de la sociedad a esas conductas, todo lo cual hace aún más amplio y complejo el objeto de estudio del sistema penal, dependiendo de la disciplina desde la que se aborde uno u otro fenómeno. ${ }^{7}$

El derecho penal es un saber teórico, dogmático y práctico. Para lograr que su aprendizaje sea significativo por parte de los abogados en formación, es necesario desarrollar metodologías y prácticas pedagógicas que permitan una comprensión adecuada de la formación profesional. Esa planificación debe fomentar un aprendizaje significativo y comprensivo, de análisis crítico de la ciencia penal, de práctica reflexiva y de constante reconstrucción de conocimiento.

En este contexto es importante reconocer el marco teórico y los esquemas analíticos que se le presentan al estudiante para la solución de un caso concreto, dispositivos conceptuales que le permiten adquirir herramientas para producción y comprensión de conocimiento, todo lo cual pasa por plantear diversos modelos pedagógicos y de reflexión sobre lo aprendido. En este sentido, la pedagogía de la docencia en el área penal ha tenido pocas reflexiones al respecto, siendo en Europa donde más se ha discutido el asunto. Por ejemplo, la academia penal alemana (Hassemer, 1984) ha propuesto el estudio del derecho penal desde la reconstrucción del expe-

7 En este sentido, son diferentes los objetos de estudio de disciplinas como la criminología, la política criminal, la dogmática penal, el proceso penal, etc. 
diente penal y en la academia española (Astigarraga, Boldova, Rueda y Usoz, 2009) se ha planteado la reflexión crítica sobre la necesidad de activar nuevas formas de enseñanza del derecho penal en el ámbito universitario.

\section{De las formas de enseñanza del derecho penal y la escritura académica}

Así las cosas, y haciendo acopio del estado del arte en materia de pedagogía y docencia universitaria, se plantea la necesidad de superar aquellas concepciones pedagógicas basadas en modelos conductistas de aprendizaje y enseñanza (Ortiz, 2004) y, así mismo, se muestra cómo diversas formas metodológicas pueden llevar a la excelencia o al "aprendizaje crítico natural" (Bain, 2007).

En este contexto, y reconociendo al estudiante como un sujeto de interacción pedagógica, es necesario abordar nuevas formas de construir conocimiento, identificando la razón de sí y el sentido de todos los participantes del acto educativo, esto es, transformando la visión de autoridad y conocimiento del docente, para dar preponderancia a la motivación y necesidades del estudiante, para convertirlo en sujeto de su propio proceso de construcción de conocimiento y no en simple "objeto" receptor del mismo.

En este sentido, se comprende el proceso de aprendizaje, no como una forma de transmitir conocimiento, sino como una construcción tanto individual como colectiva de significados (Pozo, 1996), como un proceso complejo tejido y construido de valores, representaciones, actitudes y habilidades, en el cual la realidad no es simplemente adoptada por los estudiantes, sino que es construida por la experiencia propia. Así, se dan cambios o transformaciones relevantes en el proceso de aprendizaje y se pasa del paradigma de la explicación al de la comprensión, del aprendizaje superficial al conocimiento profundo y pleno de sentido.
Es individual y colectivo porque el conocimiento es una construcción social, sentido en el cual el aprendizaje es una actividad social (no un proceso de realización individual de producción y reproducción de textos, de ideas, conceptos o conocimiento), donde lo fundamental está en brindar la posibilidad y asegurar las condiciones metodológicas para que el estudiante se desarrolle mediante la cooperación y el quehacer conjunto a niveles cada vez más superiores (Pozo, 1996). Y es significativo porque la información que el estudiante procesa o interioriza tiene un sentido o significado para él, todo lo cual replantea las posturas memorísticas y arbitrarias que se basan en la repetición, es decir, en un modelo en el que el estudiante asimila el conocimiento como simple receptor y guardador de información.

En este contexto se rescata la postura crítica de Habermas en relación con la educación y el problema de la enseñanza y la cátedra magistral, mediante la cual el estudiante recibe instrucción de procesos, aprende normas y reconoce el contenido de los conceptos. Al respecto, dice el autor alemán que el estudiante recibe información técnica indispensable que debe dominar, pero deja de lado una parte del proceso que es de suma importancia, pues deja de recibir orientaciones prácticas adecuadas al mundo de la vida, quedando ausente de su proceso la formación del carácter; en otras palabras, se aleja de la "formación intelectual general" y la "configuración armónica de la personalidad" al "aprender" únicamente la ciencia positiva (Habermas, 1987, pp. 339-340).

Es precisamente ese proceso el que muestra la importancia de la reflexión sobre el acto educativo y la necesidad de tener presente al sujeto de interacción docente, esto es, el estudiante. Este va transformando su estructura de preconceptos y conocimientos hacía una mayor complejidad y grado de abstracción; así mismo, ese nuevo conocimiento le es funcional y útil para su desarrollo y desenvolvimiento en la realidad. 
En este modelo de construcción de conocimiento, el papel del docente se transforma, pues ya no solo se preocupa por tener dominio de su tema (Bain, 2007), sino que ve la necesidad de identificar espacios motivacionales y cognitivos en donde los conceptos básicos se organizan y jerarquizan con la finalidad de construir formas de pensamiento más avanzadas. El docente no solo sabe o conoce la disciplina, también tiene habilidades para ejecutarla con destreza, y además la comprende. Eso es precisamente a lo que debe llegar en la interacción en el acto educativo con el estudiante (Pozo, 1996).

De acuerdo con ello, el conocimiento "es la información a mano", información o recuerdo que fácilmente reproduce el estudiante y que ha almacenado, de modo que, al ser interrogado, la hace explícita. El estudiante puede recordar y memorizar, pero sin saber qué es o para qué se usa el concepto. Las habilidades son "desempeños de rutina a mano". El estudiante tiene habilidad para resolver problemas y para usar su conocimiento, aunque no comprenda su génesis o cómo se llegó al mismo. La comprensión va más allá de la simple reproducción o de la habilidad bien automatizada; por tanto, la comprensión "es la habilidad de pensar y actuar con flexibilidad a partir de lo que uno sabe", como "capacidad de desempeño flexible" (Perkins, 1999, p. 70). Para Bain (2007) "los aprendizajes han de ser funcionales, en el sentido que sirvan para algo, y significativos, es decir, estar basados en la comprensión".

Pues bien, como vemos, los estudios de excelencia académica como los de Bain (2007) y de aprendizaje cognitivo como los de Pozo (1996) imponen la necesidad de reflexionar sobre los métodos que llevan al sujeto aprendiz a formas de aprehender conocimiento distintas a la tradicional. Se trata entonces de valorar qué aptitudes debe tener no solo el estudiante, sino el docente que diseña planes de estudio, los ejecuta, los evalúa e interactúa con aquel.
La forma de comprensión de la actividad docente expuesta nos muestra las diversas metas que se propone el maestro, su interrelación con el estudiante y el esfuerzo que imprime al acto educativo para motivarlo. Estudios en el campo del derecho penal muestran la necesidad de construir otras formas o métodos de docencia universitaria que logren articular la dogmática penal con la praxis penal y, especialmente, con la necesidad de que el estudiante desarrolle aptitudes reflexivas, analíticas y argumentativas en la solución de problemas penales (Astigarraga, Boldova, Rueda y Usoz, 2009). Se trata de desarrollar la posibilidad no solo de que tenga habilidades con el conocimiento, sino de que comprenda el sentido o esencia de su disciplina de manera profunda.

En este contexto es en el que se articulan la investigación pedagógica de la enseñanza del derecho penal general y la integración del aprendizaje significativo como concepto a la práctica educativa como praxis, lugar común en el que el estudiante es el actor y protagonista principal de su propio proceso de aprendizaje.

Así las cosas, una condición favorable para que se trascienda de la simple recepción de conocimiento a la comprensión crítica y profunda está dada por la posibilidad de la producción escrita del estudiante. En efecto, la escritura como proceso epistémico no solo le permitirá al estudiante reconocer la información obtenida, sino que este tendrá la oportunidad de comprenderla, apropiarla y, por qué no, transformarla en su propio proceso de aprendizaje. En otras palabras, es la oportunidad del estudiante de plantear problemas de conocimiento, preguntas sobre los temas y la realidad, y también de resolver conflictos de interpretación o de aplicación, plantear nuevas explicitaciones y evaluar la progresiva apropiación de conocimiento (Pérez, 2014)

No obstante, dicho planteamiento requiere de un entrenamiento del docente en dos dimensiones: la comprensión de la escritura académica como 
proceso epistémico y la necesaria alfabetización del docente, comprendidas ambas como procesos que le permiten ser articulador y promotor de nuevos procesos de comprensión, construcción y transformación de conocimiento.

\section{Escritura académica y alfabetización como procesos transversales de construcción de conocimiento}

Los estudios sobre la escritura académica en el ámbito universitario dan cuenta de la necesidad de comprenderla desde un enfoque epistémico, esto es, como proceso de producción de conocimiento y no como un producto acabado de la formación ni como acto de repetición mecánico, instrumental o biológico (Guzmán, 2012, pp. 5-23; Carlino, 2003). ${ }^{8}$ La escritura académica, así comprendida, está ligada a procesos de alfabetización en el ámbito universitario, que se caracteriza especialmente por la especialidad en el uso del lenguaje en cada disciplina, el contexto de habla y los diversos tipos de habilidades de quien comunica, esto es, los de exposición, descripción, análisis o argumentación (Carlino, 2003), lo que se traduce, en el campo de la disciplina del derecho penal, en un contexto de lenguaje técnico, teórico y metodológico altamente especializado y de solución de problemas fácticos con relevancia normativa o problemas dogmáticos de aplicación en la práctica judicial.

Dicha necesidad está sustentada en la perspectiva crítica de Carlino, quien valora las posturas o suposiciones generalizadas que desde lugares comunes plantea la alfabetización como algo de menor importancia (2003, p. 410). La alfabetización y la escritura académica son procesos que, como tales, están en permanente construcción, son diferenciados y permiten la construcción de conocimiento,

8 Carlino expone el concepto de la siguiente manera: "La escritura alberga un potencial epistémico, es decir, no resulta sólo un medio de registro o comunicación sino que puede devenir un instrumento para desarrollar, revisar y transformar el propio saber" (2003, p. 412). cuya importancia está en que dicha construcción es uno de los propósitos de las comunidades académicas, que ha sido descuidado, en cierta medida, en la enseñanza del derecho penal.

Uno de los principales aportes del docente universitario es precisamente su reflexión sobre el acto educativo y su participación en la alfabetización como proceso constante de formación, y en el que la alfabetización académica es entendida como aquella que permite a los sujetos participar en el contexto de la comunidad de conocimiento en la que se está formando o de la que se hace parte. Esta participación no se concibe de manera pasiva, sino que le permite al sujeto interactuar, para producir, analizar y evaluar con fines de aprendizaje en la universidad.

Según Carlino, estos componentes, que han sido objeto de desarrollos y propuestas académicas en universidades estadounidenses, canadienses y australianas, han trasformado los proyectos institucionales y la idea que se tiene de la buena o mala preparación de los estudiantes universitarios. Problemas y perspectivas que no han sido del todo pensadas y desarrolladas en el medio jurídico colombiano, por lo que en nuestro contexto no se la ha asumido aún como compromiso institucional o como impulsadora de permanente transformación en la educación profesional o implementado en el mejoramiento de las competencias del docente universitario en materia penal, 9 menos aún como proceso transformador y constructor de conocimiento de los estudiantes de derecho.

9 En este sentido, y en concordancia con lo expuesto en el primer apartado, compartimos la conceptualización sobre educación y docencia planteada por Elba Bertoni, según la cual "el docente" no puede ser únicamente un "especialista en la transmisión de conocimientos y saberes, comprometido únicamente con los aspectos cognitivos del aprendizaje, sino un profesional de la docencia que aspira a promover en los educandos un desarrollo integral de la personalidad a través de la vivencia de valores y de acciones coherentes con principios generales aceptados por la sociedad y la cultura de su tiempo" (1998). 
Ahora bien, es en esta línea que se debe pensar la escritura como proyecto de reflexión académica, viendo su recuperación como proceso de construcción y producción de conocimiento nuevo. En otras palabras, es necesario implementar procesos que permitan a los estudiantes reconocer y reestructurar lo que escriben, de manera consciente, donde su voluntad esté dirigida a la búsqueda de un fin específico con la escritura y no sea un acto mecánico o de simple casualidad o voluntad ciega. Todo lo cual requiere como primera medida que el estudiante reflexione sobre su intención al escribir, lo que va a comunicar, la estructura para hacerlo y, especialmente, su conocimiento o voluntad de hacer una escritura reflexiva y no la simple trascripción de recuerdos, conceptos o temáticas abordadas en ejercicios de transmisión de conocimiento en el aula, cuya fuente es la voz o los apuntes tomados de lo "dictado" por el profesor o memorizado de un manual.

\section{Práctica docente de la escritura como proceso epistémico}

Para lograr comprender el contenido de la escritura como ejercicio epistémico, en el segundo semestre de 2013 se plantearon reflexiones concretas al respecto y se adoptó la escritura como un medio de aprendizaje y de socialización en contextos de la enseñanza de la teoría del delito en la Universidad de La Sabana; así mismo, se reflexionó sobre la escritura como un proceso de interacción y construcción colectiva de conocimiento entre docente y estudiantes y de promoción de la reflexión práctica y la facilitación de construcción y transformación de los modelos de enseñanza, con prevalencia de un modelo procesual y no instruccional en el aula de clases. En este contexto, se adoptó como sentido profundo o estético del acto educativo la transformación de la enseñanza en una dirección constructivista social, proceso que se adapta plenamente a la escritura en el sentido que se ha venido comprendiendo.
El anterior planteamiento se deduce del ejercicio de evaluación de los escritos de los estudiantes de Derecho de la Universidad de La Sabana en un pequeño ensayo de análisis del artículo 9 del Código Penal colombiano. En este ejercicio académico se identificaron por lo menos dos escenarios de construcción: en primer lugar, el proceso de permanente reflexión y valoración sobre lo escrito, que involucra al estudiante y al docente, al escritor y al lector, quienes construyen el documento escrito de manera permanente y reflexiva (Guzmán, 2012, p. 14); en un segundo momento se identificaron la características de la comunicación del docente en el aula de clases con sus estudiantes, sentido en el cual se evidenció que no siempre los estudiantes tienen la misma percepción de los objetivos del docente ni incluso de las instrucciones y las finalidades de la escritura propuesta, todo lo cual requiere permanente retroalimentación.

Así las cosas, se corroboró que esta comprensión permite ver que la escritura no es solo un medio, en el sentido que tradicionalmente se entiende, para mejorar la memoria, para cumplir objetivos inmediatos de aprendizaje, para mostrar conocimientos adquiridos, sino que también es un instrumento de comunicación, de interacción, de aprendizaje, de reflexión y de producción de nuevo conocimiento. De comunicación, en cuanto es necesario reconocer en cada caso concreto si el docente transmitió adecuadamente lo que quería lograr con el ejercicio y si los estudiantes así lo comprendieron; de reflexión, en cuanto el docente debe reflexionar sobre lo que comunicó, lo que comprendieron sus interlocutores y lo que se debe mejorar en la práctica de la escritura. Estos dos temas se desarrollan en los siguientes dos títulos.

\section{Comunicación y objetivos de la escritura académica como proceso complejo}

Para cumplir con el propósito de reflexión sobre el acto pedagógico y los objetivos de la escritura académica, se solicitó a los estudiantes de 
teoría del delito de la Universidad de La Sabana que individualmente elaboraran un escrito de máximo dos páginas en el que se analizara el artículo 9 del Código Penal. Así mismo, se les indicó que para su desarrollo debían considerar los diferentes esquemas del delito, especialmente el finalismo y la imputación objetiva. Parte del ejercicio consistió en considerar previamente, por parte del docente, los objetivos generales, el propósito del escrito, la metodología, lo que se esperaba de los estudiantes y las dificultades que podrían afrontar. Posterior a la escritura del texto solicitado, los estudiantes diligenciaron una encuesta, con el propósito de indagar por las consideraciones que sobre los mismos tópicos podrían tener.

Una vez se elaboró el ejercicio, los estudiantes respondieron en la encuesta cuál era su percepción respecto de estos tópicos. De los 24 estudiantes solo cinco (5) plantearon que el ejercicio era analítico (21\%), la misma proporción percibió que se trataba de una competencia práctica y un $25 \%$ indicó que se trataba de un ejercicio de comprensión. El restante $33 \%$ indicó que la actividad estaba pensada para evaluar los contenidos del curso, un control de lectura o verificar si sabían el tema o lo recordaban, esto es, evaluar un proceso cognitivo de memoria.

El objetivo propuesto previamente por el docente era: "Elaborar un análisis del contenido del artículo 9 del Código Penal para identificar el nivel de comprensión de los contenidos desarrollados en el curso", es decir, que el $46 \%$ de los estudiantes percibieron la misma información y la población restante percibió o interpretó de modo diferente el objetivo de la actividad.

En la segunda pregunta de la encuesta se indagó a los estudiantes sobre su percepción acerca de su desempeño en el ejercicio. ${ }^{10}$ Estos en su mayoría hicieron un análisis de la actividad, pero

10 "Haga una reflexión sobre el trabajo realizado y escriba cómo considera usted que fue el resultado de su trabajo. ¿Cómo cree que le fue?" no respondieron la pregunta; otros plantearon respuestas diversas a la valoración solicitada, y los demás manifestaron que les había ido bien. La percepción de haber realizado un ejercicio con desempeño regular y malo fue manifestada por cuatro (4) estudiantes, esto es, menos del $17 \%$. No obstante, al leer los ensayos presentados, la proporción de estudiantes que tuvieron un desempeño no satisfactorio fue mucho mayor al detectado en las respuestas de los estudiantes en la encuesta.

La tercera pregunta que se planteó a los estudiantes estuvo relacionada con las dificultades que habían tenido en el desarrollo del ensayo. El $38 \%$ indicó que la dificultad se había debido al poco tiempo para su desarrollo, pues habían tenido solo dos horas para elaborar el ejercicio. Cuatro estudiantes manifestaron que el origen de su dificultad estaba en la falta de organización y planificación (17\%), el restante 33\% indicó falta de conocimientos, de argumentación y de estructura del ensayo. Respuestas que dejan ver la necesidad de mejorar los tiempos de preparación, estructuración, ejecución, revisión y edición final del documento y también la necesidad de planificación por parte del profesor.

De los datos obtenidos se infiere que no siempre los estudiantes comprenden o tienen claridad sobre los objetivos que plantea el docente en la actividad académica, y en ocasiones lo comprenden, pero su desempeño no es satisfactorio, a pesar de considerar lo contrario. En este contexto, el ejercicio hace evidente la necesidad de mejorar la comunicación entre docente y estudiantes, así como la necesidad de poner en común los propósitos de la tarea puesta." De otra parte, el ejercicio muestra que

$11 \quad$ Al respecto resultan muy importantes los aportes de Ángel Zabalza (2009), quien propone diez competencias como marco para concretar la identidad y el desarrollo profesional de los docentes universitarios, lo cual es un complemento ideal a lo aquí propuesto, pues el autor identifica, entre otros, la importancia de la planificación del proceso de enseñanza-aprendizaje, la necesidad de ofrecer infor- 
la escritura como proceso no consiste simplemente en transcribir, copiar o plasmar ideas o conceptos, sino que el escritor requiere de tiempo para reflexionar sobre sus propias ideas, sus propósitos y la estructura para lograrlo. Con razón, la mayoría identificó este como un problema o dificultad en su desarrollo.

Finalmente, se resalta que algunos de los estudiantes consideraron que el ejercicio de análisis estaba relacionado con la evaluación y con la recordación o memorización de contenidos y conceptos, por lo que no plantearon en sus escritos una estructura, una reflexión, un argumento, sino que en ellos predominó un estilo descriptivo y poco analítico del tema objeto de disertación. Algunos de estos aspectos repercutieron en las características de la escritura de los estudiantes, lo cual requiere un desarrollo adicional.

\section{Características de la escritura de los estudiantes de Derecho de la Universidad de La Sabana}

La valoración cuantitativa de la encuesta arrojó que en su mayoría los estudiantes tenían una percepción positiva de los resultados de su ejercicio de escritura y solo cuatro estudiantes, menos del $17 \%$, indicaron haber realizado un ejercicio con desempeño regular o malo. No obstante, al leer los ensayos, el índice negativo sería más alto que el percibido por los autores del texto. En efecto, los trabajos presentados por los estudiantes fueron valorados desde dos puntos de vista, uno formal y otro de contenidos. En los dos aspectos se encontraron valoraciones que se pueden sintetizar como se muestra en el cuadro 1.

maciones y explicaciones comprensibles, la comunicación o relación constructiva del docente con los alumnos, la necesidad de tutoriar a los alumnos, evaluar los aprendizajes, los procesos para adquirirlos y la necesaria reflexión e investigación sobre la enseñanza.

\section{Cuadro 1. Características de la escritura de los estudiantes}

\begin{tabular}{|c|c|}
\hline Aspectos formales & Aspectos de contenido \\
\hline No titularon el ensayo. & $\begin{array}{l}\text { No plantean una } \\
\text { pregunta o problema. }\end{array}$ \\
\hline $\begin{array}{l}\text { No se presenta o no } \\
\text { existe estructura en el } \\
\text { documento presentado. }\end{array}$ & $\begin{array}{l}\text { Los contenidos son } \\
\text { imprecisos o generales. }\end{array}$ \\
\hline $\begin{array}{l}\text { Frases muy concretas sin } \\
\text { conectores o desarrollo. }\end{array}$ & $\begin{array}{c}\text { No se analiza el contenido } \\
\text { solicitado. No se plantea } \\
\text { un hilo conductor. }\end{array}$ \\
\hline Faltas graves de ortografía. & $\begin{array}{c}\text { No hay producción propia. } \\
\text { Se apegan a las lecturas } \\
\text { del curso. }\end{array}$ \\
\hline No escriben conclusiones. & $\begin{array}{c}\text { No usan conectores, } \\
\text { indicadores de premisas o } \\
\text { de conclusión. }\end{array}$ \\
\hline $\begin{array}{l}\text { No hay relación de } \\
\text { contenidos. }\end{array}$ & $\begin{array}{c}\text { No plantean argumentos } \\
\text { o análisis. Son } \\
\text { descriptivos. }\end{array}$ \\
\hline $\begin{array}{l}\text { Conceptos o frases } \\
\text { literales tomados de clase, } \\
\text { ayudas didácticas o libros. }\end{array}$ & $\begin{array}{c}\text { No generan preguntas o } \\
\text { discusiones nuevas. }\end{array}$ \\
\hline $\begin{array}{l}\text { No hay citación de } \\
\text { fuentes. }\end{array}$ & $\begin{array}{l}\text { No usan fuentes } \\
\text { bibliográficas, conceptos } \\
\text { o argumentos diversos en } \\
\text { relación con los propios. }\end{array}$ \\
\hline
\end{tabular}

El anterior panorama plantea varios interrogantes. Entre ellos, la primera pregunta que surge es si efectivamente los estudiantes comprendieron las instrucciones o si el docente fue claro al respecto. El segundo planteamiento está relacionado con que el estudiante no conoce de manera clara y adecuada lo que se quiere de él en el ejercicio o desconoce los factores de evaluación en el caso concreto. En estas dos hipótesis, la percepción se genera en procesos de comunicación entre el docente y el estudiante, razón por la cual este es un proceso que el docente debe identificar y aplicar claramente, por lo que ha de informar a los estudiantes el sentido y contenido del ejercicio y sus propósitos y, en la medida de lo posible, comunicar qué espera de su desempeño y cómo lo va a evaluar. 
En este orden de ideas, la anterior situación invita a que los criterios de evaluación no solo sean conocidos por el docente, sino por el alumno, lo cual implica que este no solo vea el proceso como una evaluación, sino como producción, al autoevaluarse y reflexionar sobre el cumplimento o no de dichos criterios. En consecuencia, y como herramienta de utilidad al respecto, en el cuadro 2 se propone una matriz de evaluación de este tipo de ensayos, para definir de manera clara y previa los factores de la misma, y como guía de ruta en el proceso de escritura, autoevaluación y coevaluación.

\section{Matriz de evaluación como instrumento de comunicación y reflexión de la práctica educativa}

Como se expresó, al analizar los escritos de los estudiantes de teoría del delito se encontraron algunas dificultades conceptuales, analíticas, metodológicas y de estructura. Una vez se sistematizaron los planteamientos, las dificultades presentadas y la autoevaluación, dichas falencias se podrían reducir si el estudiante conoce previamente los factores de evaluación y además si hace una reflexión al respecto. Para ello, se plantea el siguiente instrumento guía y de valoración que tiene como insumo principal la propuesta metodológica de Guzmán (2012).

\section{Conclusiones}

La superación de concepciones pedagógicas basadas en modelos conductistas de aprendizaje/ enseñanza y la implementación de diversas formas metodológicas pueden llevar a la excelencia o al "aprendizaje crítico natural"; este, a su vez, es un escenario propicio para generar nuevas formas de construir conocimiento. Como planteamiento profundo, una nueva forma de enseñanza que dé sentido e identidad a todos los participantes del acto educativo transforma la visión de autoridad y conocimiento del docente y otorga protagonismo al estudiante, como sujeto de interacción pedagógica con capacidad de comprensión y construcción de nuevo conocimiento, y ya no como simple "objeto" receptor del mismo. Contexto que permite articular la escritura académica y la alfabetización académica como procesos complejos de aprendizaje significativo en la enseñanza/aprendizaje del derecho penal.

La alfabetización académica plantea como reto institucional a la universidad y la docencia universitaria la necesidad de que se reconozca institucionalmente que la escritura es un proceso que se construye de manera permanente por comunidades académicas y no por individuos aislados. Así mismo, que se trata de un proceso no instrumental, sino que su característica es la de permitir construir conocimiento nuevo, reflexivo y analítico en el contexto de las comunidades académicas.

En este sentido, es necesario que se asuman la escritura y la alfabetización académica en la universidad colombiana como procesos transversales en permanente construcción y no como instrumentos estáticos, biológicos, de simple competencia comunicativa o resultado de la educación. Se debe erradicar la idea según la cual la escritura tiene estas características estáticas y promover, por el contrario, la comprensión de la escritura como proceso de construcción de conocimiento, esto es, que el estudiante pase de pensar que escribe para cumplir requisitos de evaluación a escribir para construir, reconstruir, comprender o elaborar nueva pensamiento y nuevos contenidos que ahora pueda asumir como propios.

El docente, al transmitir los propósitos educativos, debe considerar la claridad en el mensaje, su estructura y los resultados que espera de sus estudiantes, de manera que estos comprendan y estén informados de lo que se espera de ellos en el proceso de producción de conocimiento a través de la escritura. Todo lo cual requiere que en la preparación de ejercicios de escritura el docente considere las diversas etapas de producción del escrito con su retroalimentación, y especialmente que considere que 


\section{Cuadro 2. Matriz de evaluación de textos analíticos-argumentativos}

\begin{tabular}{|c|c|c|c|}
\hline Criterio & Nivel inicial & Nivel intermedio & Nivel avanzado \\
\hline Platea el título del ensayo. & No se plantea el título del ensayo. & $\begin{array}{l}\text { Se plantea el título del ensayo } \\
\text { incompleto o el mismo no } \\
\text { permite percibir el contenido del } \\
\text { escrito. }\end{array}$ & $\begin{array}{l}\text { Se plantea un título del ensayo } \\
\text { que permite comprender el } \\
\text { tema y el contenido que se va a } \\
\text { desarrollar en el escrito. }\end{array}$ \\
\hline $\begin{array}{l}\text { Se evidencia una pregunta o } \\
\text { problema central en el texto. }\end{array}$ & $\begin{array}{l}\text { No existe un problema o pregunta } \\
\text { como punto de partida para el } \\
\text { desarrollo del escrito. }\end{array}$ & $\begin{array}{l}\text { Hay una pregunta como punto } \\
\text { de partida, pero no es clara, no } \\
\text { tiene contexto o su respuesta } \\
\text { no permite hacer un ejercicio } \\
\text { de análisis o argumentación. La } \\
\text { pregunta es muy amplia y no está } \\
\text { claramente delimitada. }\end{array}$ & $\begin{array}{l}\text { Hay una pregunta o problema } \\
\text { planteado con un contexto. El } \\
\text { planteamiento de la pregunta } \\
\text { es dialéctico y no se resuelve con } \\
\text { una simple respuesta afirmativa } \\
\text { o negativa. }\end{array}$ \\
\hline $\begin{array}{l}\text { Se identifica la tesis central del } \\
\text { texto. }\end{array}$ & $\begin{array}{l}\text { No se plantea la tesis central del } \\
\text { texto que se va a desarrollar, sino } \\
\text { varias ideas. }\end{array}$ & $\begin{array}{l}\text { Se plantea una tesis central, pero } \\
\text { no es clara o no se corresponde } \\
\text { con el problema o pregunta } \\
\text { planteada. }\end{array}$ & $\begin{array}{l}\text { Hay una tesis central. La tesis } \\
\text { es clara y es coherente con el } \\
\text { problema o pregunta planteada. }\end{array}$ \\
\hline $\begin{array}{l}\text { Plantea una estructura clara para } \\
\text { desarrollar el texto: introducción, } \\
\text { desarrollo, conclusiones. }\end{array}$ & $\begin{array}{l}\text { No hay una estructura del texto. } \\
\text { Se desarrollan ideas sin un orden } \\
\text { lógico o sin identificación de las } \\
\text { partes o momento en los que va a } \\
\text { desarrollar el texto. } \\
\text { Es un trabajo descriptivo sin } \\
\text { mayor organización. }\end{array}$ & $\begin{array}{l}\text { Plantea una estructura } \\
\text { incompleta. } \\
\text { La estructura es formal, pero no se } \\
\text { desarrolla claramente. Es formal y } \\
\text { no de contenido. } \\
\text { Anuncia una estructura, pero no } \\
\text { la desarrolla. }\end{array}$ & $\begin{array}{l}\text { Presenta una estructura } \\
\text { completa. Los enunciados son } \\
\text { claros y se identifica claramente } \\
\text { en la introducción el contexto, el } \\
\text { problema, la tesis, el desarrollo y } \\
\text { las conclusiones. } \\
\text { Existe coherencia entre las } \\
\text { diversas partes de la estructura } \\
\text { del texto. }\end{array}$ \\
\hline $\begin{array}{l}\text { Las ideas se presentan de manera } \\
\text { clara, ordenada y lógica. }\end{array}$ & $\begin{array}{l}\text { Las ideas son desordenadas y no } \\
\text { permiten ver un orden lógico en } \\
\text { su exposición. }\end{array}$ & $\begin{array}{l}\text { Se perciben ideas, pero no están } \\
\text { ordenadas a lo largo del texto. } \\
\text { Se presentan saltos lógicos en } \\
\text { la argumentación o no hay } \\
\text { coherencia entre los diversos } \\
\text { párrafos o argumentos del texto. }\end{array}$ & $\begin{array}{l}\text { Las ideas son presentadas de } \\
\text { manera clara, lógica y coherente. } \\
\text { No se perciben saltos } \\
\text { argumentativos. } \\
\text { Se percibe orden lógico o } \\
\text { cronológico en la exposición. }\end{array}$ \\
\hline $\begin{array}{l}\text { Usa conectores, e indicadores de } \\
\text { premisa y de conclusión. }\end{array}$ & $\begin{array}{l}\text { No usa conectores en los diversos } \\
\text { párrafos. } \\
\text { No se identifica en los } \\
\text { argumentos si se trata de } \\
\text { conclusiones, premisas o } \\
\text { subargumentos. }\end{array}$ & $\begin{array}{l}\text { Utiliza conectores en algunas de } \\
\text { las ideas desarrolladas. Algunos } \\
\text { conectores son repetidos o de uso } \\
\text { frecuente. } \\
\text { Inicia con indicadores disyuntivos, } \\
\text { pero no concluye la idea o la } \\
\text { consecuencia del indicador inicial. } \\
\text { No usa de manera adecuada } \\
\text { indicadores de premisa e } \\
\text { indicadores de conclusión. }\end{array}$ & $\begin{array}{l}\text { Usa conectores que permiten } \\
\text { identificar el hilo conductor del } \\
\text { texto. } \\
\text { Usa indicadores de premisa y de } \\
\text { conclusión de manera acertada. } \\
\text { Usa diversos conectores o } \\
\text { indicadores de premisa o de } \\
\text { conclusión sin que se repitan con } \\
\text { frecuencia. }\end{array}$ \\
\hline $\begin{array}{l}\text { Plantea conclusiones y nuevos } \\
\text { interrogantes. }\end{array}$ & $\begin{array}{l}\text { No hay conclusiones. } \\
\text { No presenta nuevas preguntas } \\
\text { o cuestiones que surjan de su } \\
\text { trabajo. }\end{array}$ & $\begin{array}{l}\text { Existen conclusiones, pero las } \\
\text { mismas no son coherentes con el } \\
\text { planteamiento del problema. } \\
\text { Las conclusiones son confusas } \\
\text { o repetición de lo escrito en el } \\
\text { ensayo. } \\
\text { Las conclusiones no son propias, } \\
\text { son citas de otros autores y no } \\
\text { permiten comprender lo que el } \\
\text { autor del texto concluye de los } \\
\text { planteamientos. }\end{array}$ & $\begin{array}{l}\text { Presenta conclusiones propias, } \\
\text { claras y coherentes frente al } \\
\text { problema. } \\
\text { Genera preguntas nuevas y dudas } \\
\text { que surgen del ejercicio de la } \\
\text { actividad propuesta. } \\
\text { Las conclusiones son propias y } \\
\text { muestran el nivel de comprensión } \\
\text { y reflexión del autor del texto. }\end{array}$ \\
\hline $\begin{array}{l}\text { Utiliza adecuadamente } \\
\text { las normas de citación y } \\
\text { presentación. }\end{array}$ & $\begin{array}{l}\text { No hay citas o referencias de las } \\
\text { fuentes usadas. } \\
\text { Presenta diversas formas de } \\
\text { citación. } \\
\text { No son claras las fuentes de } \\
\text { consulta. }\end{array}$ & $\begin{array}{l}\text { Las fuentes citadas están } \\
\text { descontextualizadas o no son } \\
\text { pertinentes al argumento } \\
\text { expuesto. } \\
\text { Usa diversas formas de citación. } \\
\text { No se distingue entre las ideas } \\
\text { propias y las ideas de otros } \\
\text { autores o fuentes. }\end{array}$ & $\begin{array}{l}\text { Usa normas y fuentes de citación } \\
\text { precisas. } \\
\text { Las citas son pertinentes y } \\
\text { aportan claridad sobre las fuentes } \\
\text { consultadas. } \\
\text { La presentación del trabajo } \\
\text { cumple con normas técnicas de } \\
\text { manera homogénea y clara. }\end{array}$ \\
\hline
\end{tabular}


se trata de un proceso y no de una actividad que se agota en un solo acto, lo cual demanda del docente reflexión sobre su propósito educativo y la adecuada comunicación del mismo al estudiante.

Los retos que impone la escritura como proceso de construcción entre sujetos de interacción educativa están mediados por la cantidad de estudiantes en el aula, los diversos propósitos de aprendizaje y las diversas formas de aprender por parte de los sujetos de la interacción educativa, todo lo cual implica para el docente la necesidad de construir prácticas de evaluación y retroalimentación entre pares, horizontales, que lleven al estudiante a reflexionar sobre sus propios errores y los de sus compañeros de clase, esto es, que comporten nuevas formas de construcción y evaluación colectiva de conocimiento. Lo anterior trae consigo nuevos interrogantes en la práctica decente, entre ellos: ¿qué metodologías permiten la retroalimentación y construcción de conocimiento en el aula, frente a la escritura como proceso epistémico?, ¿están preparados los estudiantes para evaluar a sus pares en el aula?, ¿qué instrumentos pueden ayudar al estudiante a mejorar la escritura? y ¿cómo evaluar a sus pares en el aula?

Los anteriores cuestionamientos invitan a reflexionar en los nuevos pasos que debe dar la reflexión pedagógica, más allá de considerar la escritura como proceso epistémico. Se trata precisamente de la puesta en práctica, en las condiciones actuales de la enseñanza del derecho, de los intereses de los estudiantes, especialmente de las condiciones de espacio, cantidad, técnicas y materiales, incluyendo, por supuesto, una reflexión sobre el uso de nuevas tecnologías en ese propósito de valoración de la escritura.

\section{Referencias}

Ángel Zabalza, M. (2009). Ser profesor universitario hoy. La Cuestión Universitaria, 69-81.

Astigarraga Goenaga, J., Boldova Pasamar, M. Á., Rueda Martín, M. Á y Usoz Otal, J. (2009). Metodologías activas para la docencia en las ciencias económicas y jurídicas. Una experiencia de innovación docente en un contexto dificil. Zaragoza: Prensas Universitarias de Zaragoza.

Bain, K. (2007). Lo que hacen los mejores profesores de universidad. 2 ed. Ó. Barberá (trad.). Barcelona: Universitat de Valéncia.

Bertoni, E. (1998). Acerca de las competencias profesionales requeridas para ejercer la docencia. Quehacer Educativo.

Bonilla Castro, E.y Rodríguez Sehk, P. (1997). Más allá del dilema de los métodos. 3 ed. Bogotá: Norma.

Carlino, P. (2003). Alfabetización académica: Un cambio necesario, algunas alternativas posibles. Educere, Investigación, 409-420.

Guzmán Rodríguez, R. (2012). Escritura académica en la Universidad. Chía: Unisabana.

Habermas, J. (1987). Teoría y praxis. Estudios de filosofía social. Madrid: Tecnos.

Hassemer, W. (1984). Fundamentos de Derecho Penal. F. Muñoz Conde y L. Arroyo Zapatero (trads.). Barcelona: Bosch. 
ISSN $0123-1294$ | Educ.Educ. Vol. 18. No. 2 | Mayo-Agosto de 2015 | pp. 226-242.

Universidad de La Sabana | Facultad de Educación

Jiménez Lozano, B. (1994). Epistemología y métodos de las ciencias. Perfiles Educativos No. 63.

Murillo Fernández, M. (2015). El estado del arte de la lectura y la escritura en la Universidad. Popayán: Universidad del Cauca.

Murillo Fernández, M. (2015). Los géneros académicos en la universidad: una secuencia didáctica para la enseñanza del ensayo. Popayán: Universidad del Cauca.

Ortiz Ocaña, A. L. (2004). Metodología del aprendizaje significativo, problémico y desarrollador. Hacía una didáctica integradora y vivencial. Barranquilla: Antillas.

Pérez, J. M. (2014). Didáctica de las ciencias fácticas. Educrea. Recuperado el 23 de marzo de 2014 de: http:// educrea.cl/una-vision-desde-la-didactica-de-las-ciencias-facticas-interestructuracion-alumno-conocimiento-y-el-docente-como-mediador/

Perkins, D. (1999). ¿Qué es la comprensión? En M. Stone Wiske, La enseñanza para la comprensión. Vinculación entre la investigación y la práctica (pp. 70-92). Buenos Aires: Paidós.

Pozo Municio, J. I. (1996). Aprendices y maestros. Madrid: Alianza. 